COMMENT. The EEG is particularly important in the recognition of seizures in the newborn, since clinical observation alone may not be diagnostic. An algorithm that extracts rhythmic features from the EEG by spectral analysis may identify paroxysmal patterns indicative of seizure activity, but false detections may be a concern.

In a second publication, the authors evaluated their automatic EEG method of neonatal seizure detection, using recordings from a new set of 54 patients. The average seizure detection rate in the 3 institutions providing recordings was $69 \%$, and the average false detection rate was 2.3 /hour. Fluctuations in the false detection rates, ranging from a low of 1 to a high of $4 / \mathrm{h}$, were a reflection of the technical quality and level of supervision of recordings. An experienced electroencephalographer must review "seizure" detections in conjunction with clinical observations, so that false or artifactual patterns may be excluded. (Gotman J, Flanagan D, Rosenblatt B, Bye A, Mizrahi EM. Evaluation of an automatic seizure detection method for the newborn EEG. Electroenceph clin Neurophysiol Sept 1997;103:363-369).

\title{
GABAPENTIN MONOTHERAPY FOR REFRACTORY SEIZURES
}

The results of an 8-day, controlled, multicenter study of gabapentin monotherapy in 82 hospitalized patients with refractory complex partial or secondarily generalized seizures are reported by members of the US Gabapentin Study Group. The study was conducted at 13 centers, 12 in the US and 1 in Canada, between Feb 1994 and Aug 1995. The efficacy and safety of 2 dosages, 300 and $3,600 \mathrm{mg} / \mathrm{d}$, as three equally divided doses every 8 hours, were compared after tapering and discontinuing other antiepileptic medications. Patients exited the double-blind period with the occurrence of 4 seizures (46 patients), prolonged/intensified seizures (4 patients), lack of efficacy (1), or at completion of 8 -day treatment ( 28 patients). Time to exit was significantly longer and rate of completion of the trial period was higher for patients receiving the higher $3,600 \mathrm{mg} / \mathrm{d}$ dose of gabapentin. At the higher dosage, $52 \%$ completed the study, compared to $16 \%$ at the lower dosage. Adverse doserelated events included dizziness (13\% of patients), ataxia (12\%), and somnolence (11\%). No patient exited the study due to adverse effects of gabapentin. (Bergey GK, Morris HH, Rosenfeld W et al. Gabapentin monotherapy: I. An 8-day, double-blind, dose-controlled, multicenter study in hospitalized patients with refractory complex partial or secondarily generalized seizures. Neurology Sept 1997;49:739-745). (Reprints: Dr Elizabeth Garofalo, Parke-Davis Pharmaceutical Research, 2800 Plymouth Rd, Ann Arbor, MI 48105).

COMMENT. This short-term inpatient study in adults demonstrates that gabapentin monotherapy is an effective and safe treatment for refractory complex partial and secondarily generalized seizures. In a further dosecontrolled, 26-week, multicenter study of gabapentin in 275 patients, $20 \%$ of patients completed the study, but completion rates were higher among patients who had discontinued only one AED (23\%) or had been maintained on carbamazepine $(27 \%)$ in addition to gabapentin. (Beydoun A, Fischer J, Labar DR et al. Neurology Sept 1997;49:746-752).

\section{LAMOTRIGINE OPEN TRIAL IN REFRACTORY EPILEPSY}

Lamotrigine, 5 and $15 \mathrm{mg} / \mathrm{kg} /$ daily, was administered as add-on therapy in 37 outpatient children and adolescents with refractory epilepsy and mental 